\title{
Carbon dioxide adsorption and desorption study using bimetallic calcium oxide impregnated on iron (III) oxide
}

\begin{abstract}
Bimetal adsorbent system of calcium oxide impregnated on iron (III) oxide were evaluated as a potential source of basic sites for $\mathrm{CO} 2$ capture. The adsorbents were prepared by impregnation method were calcined at 200 until $600{ }^{\circ} \mathrm{C}$. Several characterizations were carried out using XRD, BET and CO2-TPD analysis. The $\mathrm{CaO}$ loading increased the basicity of the adsorbent significantly enhance the $\mathrm{CO} 2$ chemisorption. Furthermore, it drastically reduced the desorption temperature to $310-490{ }^{\circ} \mathrm{C}$, which is important in chemisorption aspect. The $\mathrm{CaO} / \mathrm{Fe} 2 \mathrm{O} 3200$ which calcined at $200{ }^{\circ} \mathrm{C}$ was found to be most efficient. The $\mathrm{CO} 2$ chemisorption (81.29 $\mathrm{mg} \mathrm{CO} 2 / \mathrm{g}$ adsorbent) was contributed most compared to physisorption (4.64 $\mathrm{mg} \mathrm{CO} 2 / \mathrm{g}$ adsorbent).
\end{abstract}

Keyword: Adsorption; Calcium oxide; CO2 capture; Desorption; Iron oxide 